ORIGINAL ARTICLE

\title{
Legal aspects in patients with complications and sequelae after rhinological surgery
}

\author{
Manuela-Andra Savu', Codrut Sarafoleanu ${ }^{1,2,3}$ \\ 1"Carol Davila" University of Medicine and Pharmacy, Bucharest, Romania \\ ${ }^{2}$ ENT\&HNS Department, "Sfanta Maria” Hospital, Bucharest, Romania \\ ${ }^{3}$ CESITO Center, "Sfanta Maria" Hospital, Bucharest, Romania
}

\begin{abstract}
BACKGROUND. In time, the field of surgery has developed, introducing new techniques for old diseases. Along with this evolution, postoperative complications occurred and patients denounced doctors for insufficient medical care or inappropriate surgical approach. We observed an increased number of reclamations from patients who underwent rhinological surgery. All of those patients considered that medical care and the surgical act were improper, with poor outcome.

MATERIAL AND METHODS. The purpose of our presentation is to sum all the causes that motivate the patients to formulate claims and to start the legal prosecution, in order to obtain financial compensation and the doctor's conviction. We included all the patients who referred to our clinic (even if they were first treated by us or another surgical team), complaining of postoperative: persistent purulent rhinorrhea, nasal obstruction, crusts, cacosmia or anosmia, epistaxis, epiphora, unaesthetic nasal aspect. Some of these patients, before or after receiving our care, denounced the initial caregiver.

RESULTS. Their main complaints involved poor preoperative notifications regarding the surgical method, risks and potential complications, extensive surgery, wrong surgical indication, inexperienced surgical team, poor postoperative care. Even if they were first treated in our clinic or not, these patients received medical and surgical care to correct all the negative post operatory outcomes. Some of the patients still pursued the legal pathway, engaging all the resources to prove doctor's medical guilt.
\end{abstract}

CONCLUSION. To avoid medico-legal situations, guidelines need to be established for the ENT surgeons, in order to confer a healthier work environment with minimum risks and complications.

KEYWORDS: legal pathway, forensic evaluation, mistakes, surgery complication.

\section{INTRODUCTION}

When the patient thinks that his/her surgery went wrong, when his/her symptoms persist or have worsened, or when he/she is not content of his doctor, he/ she will seek for another medical opinion. Sometimes, the second doctor will tell them how badly the first intervention went, even if it is not true.

Nowadays, more and more often, patients decide to seek a lawyer in order to obtain the doctor's legal punishment and financial reparation for their distress. No doctor should find himself in the ingrate situation to defend his reputation and work, but for our tranquillity we need to acknowledge some legal aspects.

\section{LEGAL PATHWAYS}

1. The Romanian College of Physicians (RCP)

RCP is a non-governmental, apolitical, professional organization, with the reason to control and supervise the medical profession in its exercise, defending the doctor's freedom, honour and professional independence. RCP established "The Code of Medical Deontology”, with the fundamental principles of physicians' practice and other regulations ${ }^{1}$.

This institution is the first to be notified by the patient (or his caregivers) in the case of a possible medical guilt. A written complaint must be sent to RCP in maximum 6 months from the event. This letter has to 
contain: the name of the doctor, the medical facility where the care was provided (clinic or hospital), the prejudice generated and the name of the person who writes the letter, with his address and signature. In order to be archived, the intimation must be sent with a receipt or the person has to register it - it is not taken into consideration if it is e-mailed or sent by fax $^{2}$.

The College will analyse the report and will decide if there is a medical guilt, and the doctor could receive one of the following?:

- A Reprimand;

- A Warning;

- Vote of Censure;

- A fine;

- The prohibition to practice as a medical doctor or certain activities for a period ranging between 1 month and 1 year, sanction which radiates after 1 year from the expiry date;

- Withdrawal of membership of RCP, which radiates over a period of time established by the final court decision prohibiting the profession. The doctor may make a request for regaining the status of member of RCP after expiry of the period established by court order or after two years.

The College decision does not replace or cancel the civil, legal, administrative or financial liability.

Some sin ecva non conditions must coexist in order to build a case:

- A relation with the patient is compulsory - a duty, a professional obligation of the doctor.

- That duty must be fulfilled at a certain standard level, according to the speciality, specialisation and experience.

- Infringement of the medical obligations - non accomplishment or vicious realization.

- A prejudice was made.

- Cause-effect connection between the medical obligation and the harm claimed by the patient.

\section{The Criminal (penal) Prosecution}

In this situation, the doctor is judged regarding important body harm. This is difficult to prove. The prosecution needs a forensic evaluation in order to establish guilt and intention. Often, the decision is not to continue with the criminal pursuit.

The doctor can be convicted in order to protect the social values: life, health and medical care. The RCP will uphold his license to free medical practice.

The substantial criminal legislation in Romania does not provide separate offenses for cases of malpractice, as defined by Art. 653 par. 1 b of Law 95/2006 on Healthcare Reform.

However, in cases with serious consequences of the inappropriate conduct of the doctor, comparing to regulated professional standards (imposed by Law
95/2006), the inquiry competence and their solution lies with the judicial bodies (prosecutors and courts).

The practitioner's actions, with critical consequences for the patient's health, can be registered as offenses: negligence body injury and manslaughter.

Involuntary bodily injuries (provided and punished by Art. 196 of the Criminal Code) is the act in which, by fault, the active subject (in this case the doctor) causes physical suffering, injuries or health damage to a person, whose gravity is measured by days of medical care less than 90 days. Assuming the theory above, the initiation of criminal proceedings starts with the complaint of the patient, who considers himself person injured. Reconciliation of the parties removes criminal liability. Jurisdiction to prosecute belongs to the Public Prosecutor Office in whose territorial jurisdiction the facility where the doctor works belongs to.

"Manslaughter due to non-compliance with laws or measures for the provision of a profession, an occupation or to perform certain activities" is provided and punished by Art. 192 of the Criminal Code. In this case, the outset of criminal proceedings is made by the patient's caregivers or ex officio by the judicial organs' criminal investigation. In this case, as well, the jurisdiction to prosecute belongs to the Public Prosecutor Office in whose territorial jurisdiction the facility where the doctor works belongs to.

\section{The Civil Prosecution}

The civil action starts when initiated by the patient - if he suffered prejudice, without important body harm, he wants to sue the doctor only for remuneration. In order to start this path, he has to pay a tax for the trial that will start. This tax is calculated as a percentage of the reimbursement asked.

The civil court has to establish how much cost:

- The pain, the suffering - in Romania this has little consideration,

- The moral endurance (human humiliation),

- Direct damage caused: the patient presents all payment documents related to all the things he had to pay, in order to restore his physical and psychic status.

\section{WHAT IS MALPRACTICE?}

Malpractice is professional error committed in the practice of medicine or medical-pharmaceutical field, tortious for the patient, involving civil liability of medical staff and supplier of medical products and services, health and pharmaceuticals ${ }^{4}$.

Malpractice sums the negligence and incompetence of the doctor, in case of established medical guilt. It is difficult to demonstrate. 
In Romania, malpractice is covered by a disputed law: 95/2006, with numerous articles. Art. 668-674 from Title XV starts a special procedure to determine the cases of the healthcare providers (doctor, nurse, etc.) professional liability, in the civil way. It must be differentiated from the art. 442-451 in the same law, which establish the doctor's disciplinary liability - its aim is to assess if the doctor violated laws and regulations of the medical profession, the ethical code or the RCP statute.

The medical staff answers in the civil way for the damages resulted from error, carelessness or insufficient medical knowledge in the exercise of profession through individual acts of prevention, diagnosis or treatment ${ }^{5}$.

The medical staff is not liable for damages and losses caused during practice ${ }^{6}$ :

$A$ ) When they are due to working conditions, poor endowment with equipment for diagnosis and treatment of nosocomial infections, side effects, complications and risks of generally accepted methods of investigation and treatment, of sanitary materials hidden defects, medical devices, equipment and substances used in medical and health care.

$B$ ) If they are direct or indirect consequences of written instructions, or proven, of the chief supervisor. In this case, responsibility rests with the person who formulated the indication.

C) If they are a direct or indirect consequence of the application of the rules and legal regulations.

D) When acting in good faith in emergencies.

All the working medical personnel must have a malpractice insurance needed in cases of professional liability for damage caused by the medical $\mathrm{act}^{7}$.

The malpractice policy covers a payment agreement between the patient and the insurance company. If the patient takes the money from the insurance he will sign an agreement that he will not have other requests. Even if he received money from the malpractice insurance company, he can ask for more in the civil court.

\section{PREVENTIONS FOR DOCTORS}

As a doctor, always remember that the patient's chart is a legal document! Write it with accuracy! Take notice that, in case of any investigation, all the experts' conclusions or opinions (requested by the justice court) will be given having the base of this chart! Daily evolution of the case must be documented with consideration including: day, month, hour and minute and the person who writes it.

It is very important to read with caution the patient's investigations. Also, do not ignore the medical records forwarded by colleagues or other specialists! Follow their recommendations! If you do not agree with those, talk to your patient and explain to him why; register all this in his chart!

If the pathology exceeds your qualification (or further investigations are needed) refer the patient to another specialist or to a medical center! Arrange for the patient to execute all the investigations needed!

Do not ever forget about the informed consent! This is necessary for any invasive procedure or for the patient's declination about a certain recommended treatment.

Before and after the surgery, spend a few minutes with your patient, even some more than usual! Consider this the time given for your own tranquillity. Also, be kind, calm and polite with your patients! Usually, they do not intend to sue doctors who have been gentle with them, who treated them with respect, attention and empathy.

Answer your patient's call! When you gave them your number, you probably thought that things can worsen. Even if you are on holiday, after work hours or on call, answer the phone or call back! If you are not available, make sure that one of your colleagues is and the patient knows how to reach him! When you will have access to the register, record the conversation, including time and advice given! Contract an upgraded malpractice insurance policy! Read carefully all the terms before signing it, especially those written with small letters (e.g. Sometimes the insurance cannot be valid for patient residence in United States, Canada or Australia)!

\section{The consent form}

In order to be subjected to methods of prevention, diagnosis and treatment, with potential risk to the patient, after the doctor/ dentist/ nurse/ midwife, the patient's written consent is required. In order to obtain his written consent, the doctor/ dentist/ nurse/ midwife is indebted to present the information with a reasonable scientific understanding of its power. The information should include: diagnosis, nature and purpose of the treatment, the risks and consequences of the proposed treatment, viable treatment alternatives, risks and consequences, prognosis without treatment ${ }^{8}$.

The consent form represents the patient's declaration in which he expresses his will and he authorizes the doctor to proceed, or not, with the surgical intervention.

The Romanian Ministry of Health provided us one standard consent form for all the surgical manoeuvres, including those in ENT. Our clinic considers it an evasive document, exposed to interpretation, so we have decided to draw up a consent form for every surgical ENT procedure, including a separate one for the endoscopic naso-sinusal approach. Those informed consents were appreciated and validated by a well-known Medical Forensic Professor. 
According to the Romanian law, all the specifications that are not illegal (that do not violate the law) are recognized and accepted like an agreement between parts. Transforming a general consent form into a specific one is auspicious.

\section{Anamnesis}

Anamnesis is a very important step in evaluating a patient. Record a correct case history - any previous intervention for the same disease? What type? As a doctor, you have to be aware that the patient can be evasive or can forget some important aspects.

Also, it is important to know if there is any allergy (e.g. antibiotics, iodine, latex, lidocaine, etc).

Past medical history? Any chronic disease? Even if for the patient it has no connection with the current rhinosinusal disease - e.g. cilia abnormalities, immunodeficiency, cystic fibrosis - any of these can affect the intervention outcome.

\section{Is imaging important?}

Yes, a lot. Imaging is important especially for the preoperative anatomic evaluation. Ask for a thin-cut CT-scan in all 3 axes. CT-scan is internationally considered to be the gold standard diagnostic study before rhinosinusal interventions. Do not settle only with radiography or an MRI examination ${ }^{9,10}$.

Remember that in Romania there are lots of centers where it can be performed and the cost for a craniofacial CT-scan (native) is not that high, with prices starting at $28 €$, or it can be free of charge if the ENT specialist provides a recommendation.

\section{RULES IN CASE OF LEGAL PROCEEDING NOTIFICATION}

- Do not be scared and do not panic!

- Do not discuss it with your colleagues, relatives or friends and do not divulge confidential information to unauthorized people! Do not talk to the press - these days they are more interested in ratings rather than the truth. At the end, you will have plenty of time to tell your story.

- Notify your malpractice insurance firm in maximum 3 days from the moment you have been aware of this notification.

- Keep your calm and find yourself a lawyer! It is best to have a good start with a professional guardian of your interests; a lawyer specialized in medical law cases. Inform him of all facts, even those that might be unfavourable to you! Analyse with him the medical documents and try to find any inconsistency!

- Ask your lawyer to indicate a good forensic expert who you could trust. You will need him as expert part.

- Do not listen to advice from so called benevolent people!

- Do not accept the same lawyer who defends the institution you work in or other doctors - you could have different interests from theirs.

- Remember the history of the case! Write it down with details! Recover all possible documents regarding the patient (e.g. clinical photos, copy of documents), even if they are not attached in the original files! Maybe you will need them later.

- Do not call or visit the patient! Do not get in contact with him in any way! Do not ask him for any explanations! Do not apologize and do not even think to threaten or offer him money!

- Do not declare anything to anyone by yourself! Give statements - to the Police, to the RCP or to the Public Sanitary Department, etc. - only in the presence of your defender, chosen by you!

- Do not request the clinical chart to make changes in it! Do not allow anyone to do that! In this phase, a copy of the original chart is already in the hands of authorities. Discordance between one and the other will not look good.

- Do not be superficial about the statements you give! Sometimes only one declaration is needed to be given in order for the board to complete the case. This is your chance to finish with everything.

- Do not blame other doctors / colleagues who gave care to the same patient! Your duty is not to find the guilty. You just have to motivate your actions and protect your medical practice.

- You will hear and receive accusations worse than reality, even some that do not make any sense. All of them are part of the game.

\section{WHY THINGS DO NOT GO AS PLANNED?}

Usually, things do not go as planned because of endoscopic sinus surgery (ESS) over indication or because we are dealing with an inexperienced surgeon. ESS performed with a meticulous technique significantly decreases patient morbidity and trauma ${ }^{11}$.

Our evidence-based medicine has a common statement: we cure diseases and we operate on patients, not CT scans. With a clear CT-scan, even if the patient claims disturbing symptoms, it does not mean we have to do surgery, because we will not cure the symptoms with surgery. And maybe, sometimes, we can worsen them (Figure 1, Figure 2).

Do not forget the basics and first investigate: nasal and rhinopharyngeal bacteriologic and fungal cultures; intraluminal contrast radiography of the upper gastrointestinal tract and/or upper gastrointestinal endoscopy. 


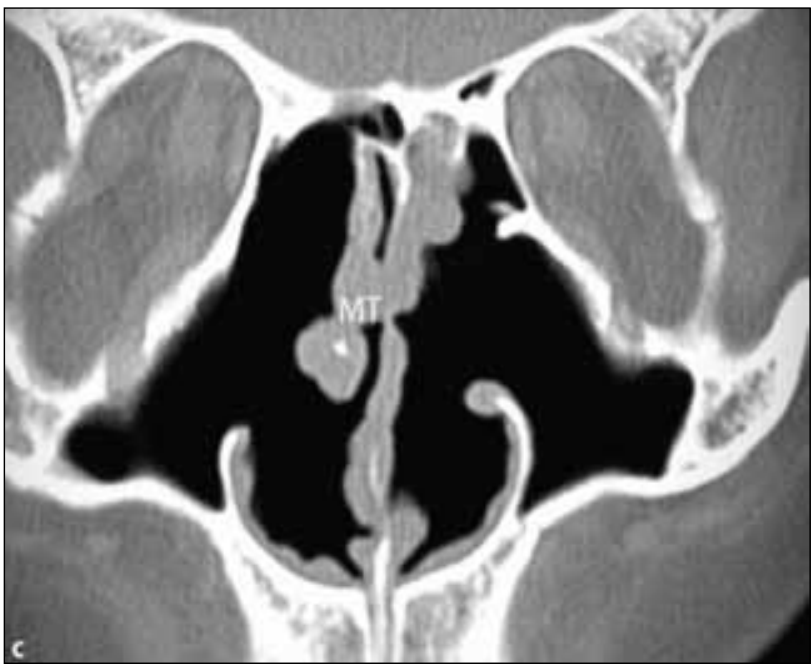

Figure 1 Cranio-facial CT-scan, coronal slice. Postoperative aspect of an ESS for chronic rhinosinusitis. Absence of both inferior turbinates and left middle turbinate, lack of ethmoidal cells, with a wide non-physiological opening of both maxillary sinuses.

\section{POSTOPERATIVE COMPLICATIONS}

\section{Purulent rhinorrhea with cacosmia}

After surgery, rhinorrhea may be:

- Persistent - caused by incomplete sinusal approach - with the persistence of purulent reservoirs - e.g. unopened ethmoidal cells (Figure 3);

- De novo - because no intraoperatory antibiotic was administrated;

- Recurrent - after surgery, a short period of clinical recovery, followed by the reappearance of symptoms - e.g. in the case of odontogenic purulent acute rhinosinusitis with a persistent infected

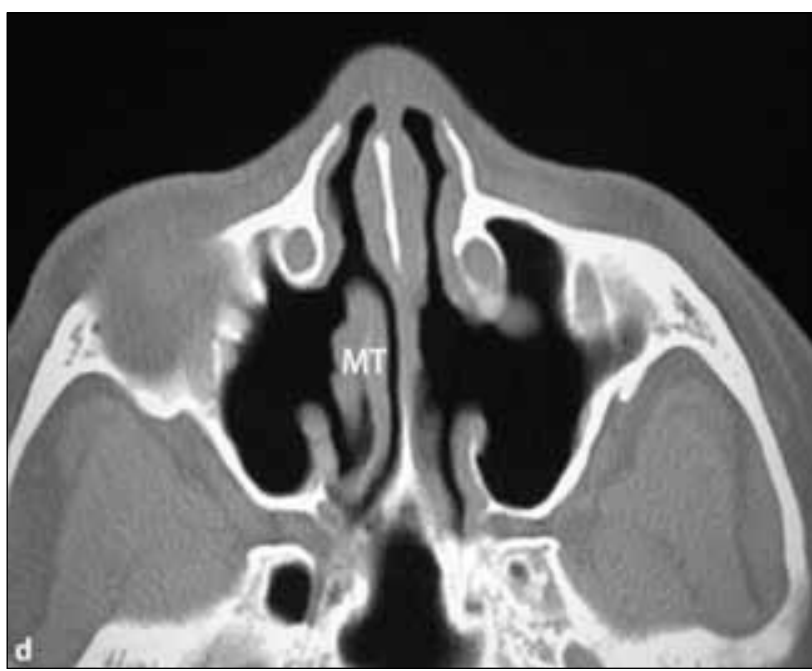

Figure 2 Axial section native CT-scan from the same patient.

dental root. Also, stomatological iatrogeny is an important source of maxillary sinus infection ${ }^{12}$.

It is important to know the anatomic landmarks and the proximal vital structures as the brain, the eye, the skull base, the large vessels. Always remember that each individual has their own anatomic variations and those must be recognised and measured. Knowing all of this, it is not surprising that ESS has become the most common cause of litigation in the ENT field ${ }^{13}$.

\section{Foreign bodies}

Unilateral purulent rhinorrhea reported by the patient after a septoplasty intervention. During the endo-
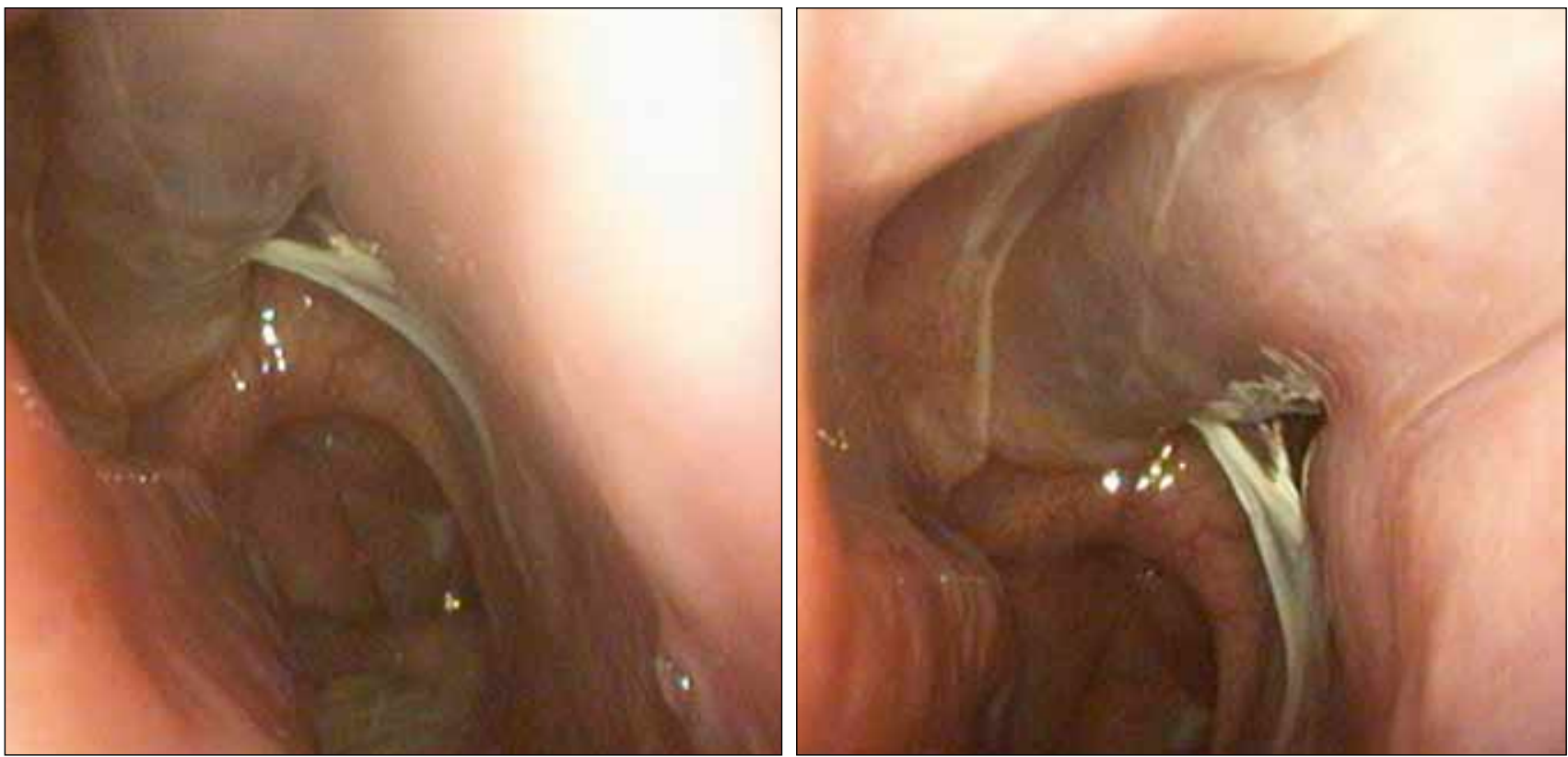

Figure 3 Endoscopic view of the right nasal cavity - persistent rhinorrhea after ESS - some ethmoidal cells have not been opened 


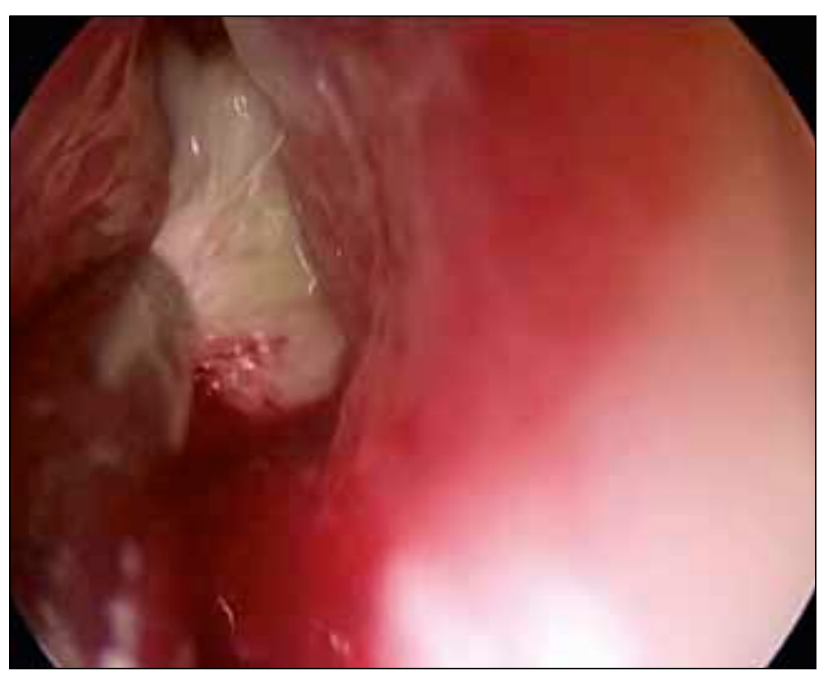

Figure 4 Endoscopic view of the right nasal fossa. The foreign body is located in the ethmoidal roof.

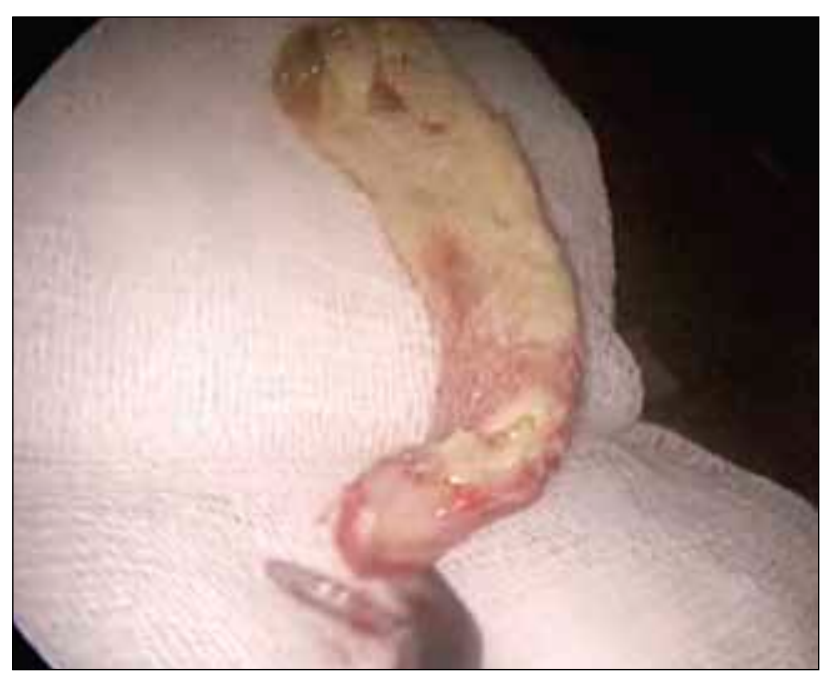

Figure 5 The aspect of the cotton pad (soaked with puss) after removal.

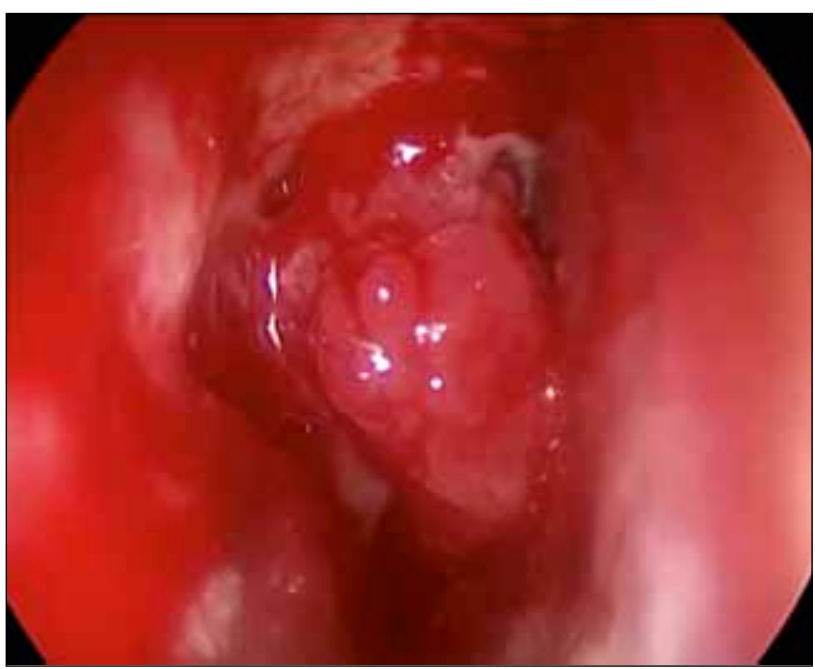

Figure 6 The aspect of the mucosa after the removal of the foreign body local inflammation, friable mucosa, easily bleeding.

scopic examination we identified a cotton pad blocked in the ethmoidal roof. General anaesthesia was necessary in order to remove it (Figures 4-6).

\section{Rhinoplasty}

Surgery correcting nasal deformity sometimes can affect the basic role of the nose: respiration. Without postoperatory proper care, the nose heals with scar, synechiae, disturbing rhinorrhea and insufficient inspiratory flow (Figure 7-9).

\section{WHO HAS THE BLAME?}

All the medical personnel can be responsible for an error: doctor, nurse, pharmacist, midwife who offer medical services. Civil liability regulated by this law does not remove the criminal liability, if the act that caused the damage is a crime under the law ${ }^{14}$.
- Can it be the patient's fault?

Yes, if he did not come for check-up or did not use the treatment recommended at home. Or maybe, some general undiagnosed disorders coexists - e.g. Wegener granulomatosis - that delay healing.

- Can it be the doctor's fault?

Yes, when he provided poor postoperatory care: he did not ask the patient to come for check-ups or his care was not sufficient.

How frequent shall we call the patient for followup? In the discharge papers we recommend daily follow-up after ESS for the first 5 days; after that, the patient is called once a week for a month. Every visit must be recorded.

- Team or individual liability?

The resident doctor has no legal responsibility. For every surgical manoeuvre he must be supervised by a specialist doctor. 


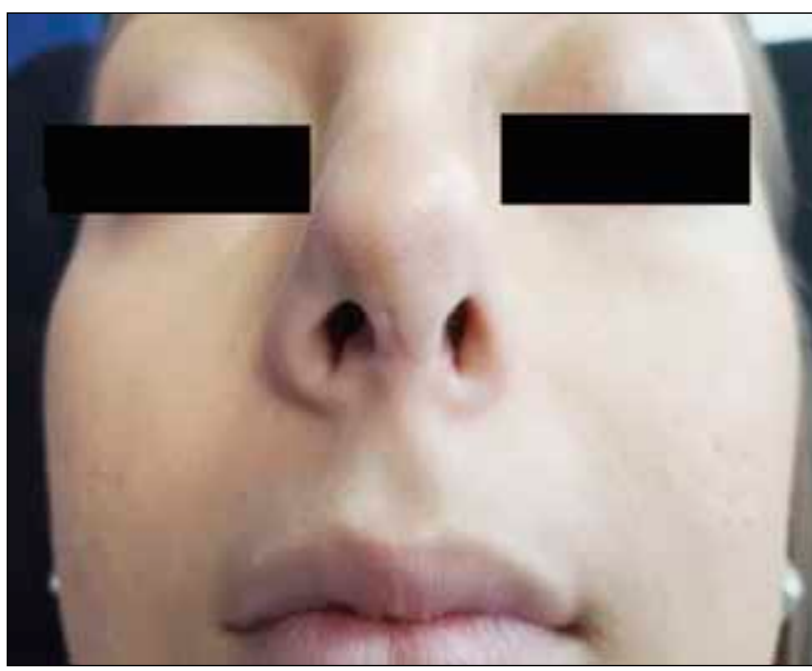

Figure 7 Scar of the columella with nostril asymmetry after two interventions for nasal dysmorphia.

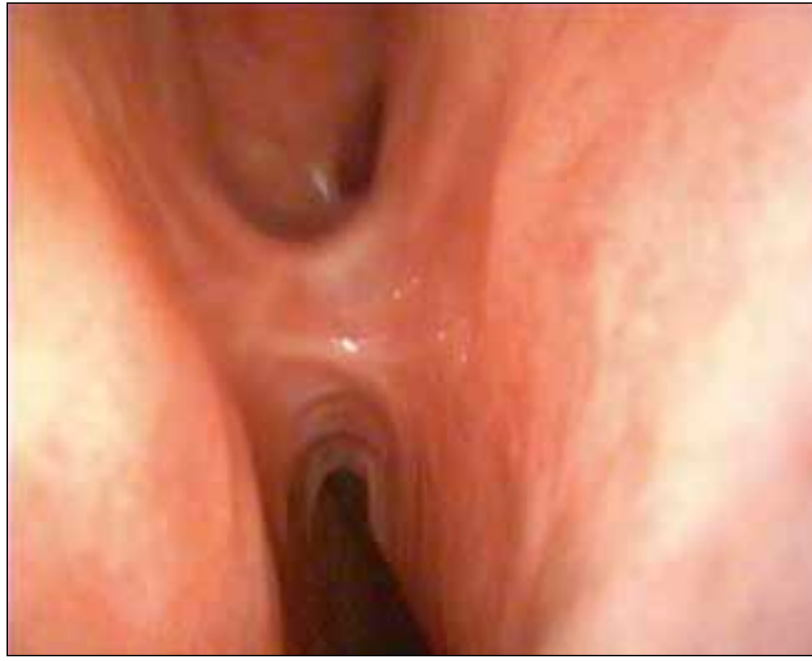

Figure 8 Endoscopic view - septo-turbinate synechiae on the left nasal fossa

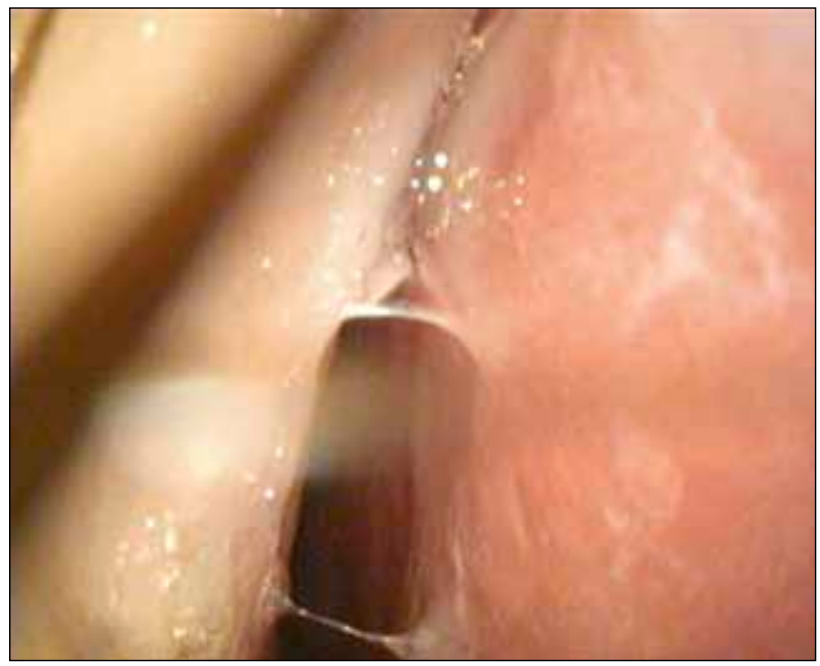

Figure 9 Right nostril: the angle formed by the crus lateralis and the nasal septum is narrowed, collapsing during inspiration.

\section{NOWADAYS IN ROMANIA}

It is almost impossible to prove the criminal intention of a doctor, his actions pointing to do intentional harm. This leads to Not Start the Criminal/Penal Pursuit.

If the patient still believes that he suffered some injury (physical, mental, sentimental) he can start the civil indictment. But he has to pay a tax to the state court - a percent of the reimbursement asked.

In Romania, there is a general lack of protocols in medicine practice. In hospitals, protocols are not familiar for every employee; either protocols are not written or they are not implemented, even though each hospital can create its own protocols regarding everything, especially the right conduct / behaviour in certain cases.

\section{CONCLUSIONS}

To avoid medico-legal situations, guidelines need to be established for the ENT surgeons, in order to provide a healthier work environment with minimum risks and complications. Doctors must be well informed about their rights and their obligations. Inexperienced surgeons must know their limits and acknowledge all the possible complications that may occur, being prepared to solve them with professionalism, keeping the medical calling in its honourable position.

Acknowledgements: I would like to thank Bogdan Cioflan - Attorney at law - for his expert advice and encouragement.

Conflict of interest: The authors have no conflict of interest.

Contribution of authors: All authors have equally contributed to this work. 


\section{REFERENCES}

1. Code of Medical Deontology of the Romanian College of Physicians Available at: http://www.cmr.ro/code-of-medical-deontology-of-the-romanian-college-of-physicians/. Accessed September 7, 2016

2. Cum se reclama un caz de malpraxis. Available at: http://www.cmr.ro/ cum-se-reclama-un-caz-de-malpraxis/. Accessed September 5, 2016.

3. High Commission of Discipline. The Romanian College of Physicians. Disciplinary liability for doctors in Romania. The deontological code. 2011. Available at: http://www.cmr.ro/raspunderea-disciplinara-a-medicilor-in-romania/ Accessed September 3, 2016.

4. According with the provision of Law No. 95/2006 on healthcare reform; Art. 653, align. 1, letter b.

5. According with the provision of Law No. 95/2006 on healthcare reform; Art. 653, align 2.

6. According with the provision of Law No. 95/2006 on healthcare reform; Art. 654, align 2.

7. According with the provision of Law No. 95/2006 on healthcare reform; Art. 667-678
8. According with the provision of Law No. 95/2006 on healthcare reform; Art. 650, align 1-3.

9. Bhattacharyya N., Lee L.N. - Evaluating the diagnosis of chronic rhinosinusitis based on clinical guidelines and endoscopy. Otolaryngol Head Neck Surg., 2010 Jul;143(1):147-151.

10. Pondrom S. - CT Scanning of the Paranasal Sinuses: Indications, Utilization, and Radiation Risks. Available at: http://www.enttoday.org/ article/ct-scanning-of-the-paranasal-sinuses-indications-utilization-andradiation-risks/. Accessed 5 July 2016.

11. Stammberger H., Posawetz W. - Functional endoscopic sinus surgery. Eur Arch Otorhinolaryngol., 1990;247:63-76.

12. Sarafoleanu C. - Patolgia infecto-inflamatorie otolaringologica. In: Popescu I., Ciuce C. (sub red), Sarafoleanu C. (coord.) - Tratat de chirurgice Vol I Otorinolaringologie si chirurgie cervico-faciala, Ed. Academiei Romane, Bucuresti, 2012;p:28-29.

13. Pelausa E.O., Smith K., Dempsey I. - Orbital complications of functional endoscopic sinus surgery. J Otolaryngol., 1995;24:154-159.

14. According with the provision of Law No. 95/2006 on healthcare reform; Art. 653 align 5. 